\title{
ENTRE LARANJAS E LETRAS: PROCESSOS DE ESCOLARIZAÇÃO NO DISTRITO-SEDE DE NOVA IGUAÇU (1916-1950)
}

por Amalia Dias. Rio de Janeiro: Quartet/Faperj, 2014, 523 páginas. ISBN: 9788578120917.

O meu convite à leitura se refere ao livro da historiadora Amália Dias, fruto de alentada tese de doutorado, defendida em 2012, no Programa de Pós-Graduação em Educação na Universidade Federal Fluminense, sob a orientação da professora Cláudia Maria da Costa Alves, de cuja banca, aliás, tive o privilégio de fazer parte, por dever e graça do ofício.

Publicado em 2014 pela editora Quartet, o livro se constitui em referência obrigatória para os pesquisadores e estudiosos da história dos processos de escolarização na Baixada Fluminense e no Estado do Rio de Janeiro. Com ênfase sobre a região geopolítica demarcada pelo distritosede de Nova Iguaçu, entre os anos de 1916 e 1950, a pesquisa contribui significativamente para a compreensão da história da educação em regiões ainda pouco estudadas, como é o caso do interior do Estado do Rio de Janeiro.

De modo inovador e competente, a autora realiza belíssima operação historiográfica, promovendo rara e necessária discussão teórica sobre os conceitos de local, regional e nacional. Os conceitos de território e região e a definição dos campos que constituem a história local e a história regional são discutidos, do ponto de vista teórico, a partir do prisma que articula as escolhas do historiador e os lugares de produção da escrita. Afasta-se, assim, uma concepção estática e externa ao objeto de estudo, próprias de tradições historiográficas que tomavam o território, a região, a história local, regional e nacional como dados. Esta reflexão teórica é um dos pontos altos do livro e oferece contribuição importante para a problematização do campo de pesquisa. Ao compreender o território 
para além dos seus limites geográficos, mas, ao contrário, privilegiando a concepção de espaço social construído historicamente, a autora analisa as dinâmicas sociais, econômicas, políticas, culturais e demográficas, que o constituíram. Para tanto, a autora tece considerações sobre a história da escolarização na cidade de Nova Iguaçu, considerando as múltiplas dimensões mencionadas.

O seu objetivo geral com o estudo foi o de identificar as forças atuantes na sociedade e suas formas de participação no processo complexo de organização das escolas no município, entre os anos de 1916 a 1950. Para tanto, as disputas e a articulação entre projetos locais, estaduais e nacionais foram objeto de análise e de minuciosa problematização. $\mathrm{O}$ protagonismo, os conflitos e as perspectivas distintas sobre as funções sociais da escola, sob a ótica dos grupos políticos e intelectuais da própria região, foram considerados pela historiadora. Cabe salientar que, no período em análise, emergiram projetos conflitantes sobre as funções sociais da escola e dos processos de escolarização em espaços e territorialidades distintas, bem como a produção de representações contraditórias sobre os significados de urbano e rural, cidade e campo. Embora cidade e campo fossem interdependentes e indissociáveis, na lógica da expansão transnacional do capitalismo, muitas vezes foram representados como espaços opostos, hierarquizados, antagônicos, desiguais.

No campo da educação, entre finais do século XIX e as primeiras décadas do século $\mathrm{xx}$, o sentido de difusão da escola primária incluía a tentativa de reverter os altos índices de analfabetismo, ao mesmo tempo em que se buscava promover a interiorização do Estado republicano, via escola, para integrar aos projetos nacionais as populações urbanas e rurais, das periferias das metrópoles urbanas às regiões camponesas. $\mathrm{Na}$ perspectiva de muitos intelectuais e autoridades públicas, o reforço do nacionalismo só seria possível com a disseminação da escola primária. A educação popular passou a ser vista como redenção da sociedade brasileira e foi tomada como portadora da incumbência da salvação dos males da sociedade. Como representantes do debate sobre a educação das populações rurais e camponesas, intelectuais considerados como defensores do "ruralismo pedagógico» se engajaram na elaboração de projetos, políticas e reformas educacionais no âmbito dos Estados e dos municípios, num processo que se intensificará nas décadas seguintes, alcançan- 
do as políticas federais do Ministério da Educação e Saúde, estruturado em 1930. Os ideais educacionais do chamado "ruralismo pedagógico» preconizavam uma mudança na educação escolar, principalmente, em temas que abrangiam a questão curricular, o calendário e a formação de professores em contraposição aos padrões hegemônicos de ensino urbano historicamente estabelecidos. Os ruralistas buscavam mudanças na realidade nacional com o intuito de fixar o homem do campo no seu habitat natural, através de uma educação pragmática que contemplasse todas as necessidades do meio rural, via de regra, promovendo a relação direta entre a educação escolar e os mundos do trabalho. Por meio a articulação entre cultura escolar e mundos do trabalho, a ideia mestra era a de que a educação seria o sustentáculo da produção econômica e da reprodução da vida social no campo. Nessa perspectiva, o controle do êxodo rural também beneficiaria o desenvolvimento das cidades e da modernidade urbana, pois, supostamente, a fixação do homem no campo seria capaz de conter o crescimento populacional nas favelas e o inchaço dos grandes centros tenderia a ser amenizado. Esse ideal de formação do homem do campo, Amália Dias pôde observar, operando com os jogos entre as escalas locais, regionais e nacionais, considerando as especificidades históricas da escolarização, no caso de Nova Iguaçu, no Estado do Rio de Janeiro.

No primeiro capítulo do livro de Amália Dias, intitulado «Pela lavoura, higiene e instrução», destaca-se, especialmente, a relação entre os processos de escolarização e o progressivo dinamismo econômico na região, com a introdução do cultivo de laranjas no município de Iguaçu, a partir de políticas fomentadas pelo governo de Nilo Peçanha (que foi governador do Estado e em seguida presidente da República), com o apoio do Ministério da Agricultura, Indústria e Comércio (MAIC). Por meio da análise do periódico Correio da Lavoura, e dos grupos que estiveram à frente deste órgão de imprensa, a autora recompõe a trama de projetos políticos, sociais e econômicos com as políticas encaminhadas por sucessivos governos hegemônicos no cenário fluminense. Neste ponto, embasada no cruzamento de documentação diversa, a autora demonstra, com clareza, a articulação entre as dinâmicas locais, regionais e nacionais. As medidas para «modernização» do município, implementadas por frações de classe hegemônicas, em meio às tensões e disputas por lugares de poder, produziram o «mito da idade de ouro», que enfatizavam a pujan- 
ça econômica e o progresso de Iguaçu. Considerando a diversidade e a heterogeneidade dos processos de escolarização na região, a autora relativizou a aparente homogeneidade inscrita na definição administrativa e política de um território, chamando a atenção para as disparidades e as desigualdades entre os diferentes distritos e a irregular oferta e distribuição das escolas no município, desde aquelas custeadas pelos cofres públicos como também as financiadas pela iniciativa dos particulares. Assim, manejando dados estatísticos, relatórios, artigos e editorais da imprensa local, a autora demonstrou o quanto o rural e o urbano, no distrito-sede de Nova Iguaçu, expressaram experiências simultaneamente semelhantes e distintas de escolarização, destacando as disparidades entre instituições, níveis de ensino, a circulação de modelos, práticas e sujeitos sociais heterogêneos no mesmo município.

No segundo capítulo, intitulado «Fazer-se Estado fazendo escolas», a constituição da rede de escolas e sua expansão pelo interior do Estado do Rio de Janeiro, bem como a análise do aparato burocrático, legal e administrativo, em âmbito estadual e local, são objetos do estudo, a partir do referencial teórico de Estado Ampliado de Antonio Gramsci. Com isso, foi possível à pesquisadora reconstituir o perfil de parte das escolas existentes no município de Nova Iguaçu, nos anos de 1930 e 1940, investigando, sobretudo, a constituição da cultura escolar, a socialização de crianças e jovens em escolas públicas e particulares da região. Estão presentes na análise as contradições entre as tentativas de homogeneização e uniformização da escola por parte do Estado em face à pluralidade das experiências e diferentes condições de funcionamento das escolas.

Os mapas de frequência escolar —-ferramentas da inspeção estadual das escolas, ao fornecem indícios que permitem situar a distribuição nas escolas em um mesmo município, revelam a expressiva presença de escolas públicas estaduais e municipais de ensino primário em Iguaçu e no distrito-sede- nas décadas de 1930 e 1940. A escola isolada predominou como tipo de organização das escolas, tanto em áreas rurais quanto urbanas do munícipio. A presença de escolas foi maior no distrito-sede em todo período coberto pela pesquisa. A localização das escolas no distrito-sede revelou a maior presença de escolas de localização urbana, nas principais ruas e no entorno central do distrito-sede. 
Quanto ao formato das escolas, da seriação de ensino ofertada, da organização de turnos, dos professores e alunos por elas distribuídos, nota-se a existência de múltiplas experiências de escolas primárias no município, sendo, contudo, predominante a escola isolada com até as três primeiras séries do ensino. No tocante a organização do trabalho docente, a análise demonstra que docentes, turnos, séries do ensino e classe escolar eram variáveis agregadas de diferentes modos, revelando a coexistência de tipos diferentes de escolas e as apropriações realizadas dos termos classe, série, turno, em face da implantação de constantes reformas legislativas do ensino primário. A comparação da movimentação de alunos por classes, séries e turnos restitui um cotidiano diversificado. No entanto, é possível notar a maior incidência de matrículas e de permanência de alunos nas duas primeiras séries do ensino.

As imbricações entre os projetos ruralistas econômicos e educacionais e as políticas educacionais, em nível local, regional e nacional, são temáticas aprofundadas no terceiro capítulo do livro, sob o título que nomeia a obra publicada, «Entre laranjas e letras». Pela sua leitura, compreendese que os grupos agrários dos estados, secundarizados na correlação de forças no cenário nacional, empenharam-se no combate à monocultura na campanha pela diversificação dos produtos, o fomento à produção em propriedades parceladas, a adoção da mão de obra nacional e a modernização dos modos de cultivo, fatores que constituíram os pilares do chamado movimento ruralista observado no período. No caso específico do Estado do Rio de Janeiro, este movimento foi observado por meio da análise das Escolas Típicas Rurais, no pós-1930, e o cotejamento dos projetos de escolarização em variadas escalas, a partir da problematização das representações, e das relações sociais concretas, tecidas sobre os meios rural e urbano e sobre os múltiplos significados da escola. Como laboratórios para o exame dessas representações, a autora privilegiou a análise de momentos solenes na história local, como a visita de Getúlio Vargas, então presidente interino, em 1931, e as comemorações pelo centenário da fundação da Vila de Iguaçu, em 1933, eventos significativos para a redefinição das relações de força e das alianças entre os grupos locais citricultores e as elites políticas estaduais e nacionais.

Temáticas como a higiene, o saneamento, a modernização urbana, o civismo, o desenvolvimento agrícola e suas relações com a educação 
e a instrução escolarizada, entre outras questões, foram desenvolvidas pela autora no quarto capítulo ( «Fazer-se cidade fazendo escolas, fazerse escola fazendo a cidade»). Nesse capítulo, Amália Dias dedicou-se a reconstruir múltiplos significados em disputa na construção da cidade e das representações do urbano, no processo de escolarização que então se forjava. Examinou os vínculos construídos pelas elites intelectuais locais entre escola, trabalho e atividades produtivas do município, por meio de campanhas, discursos, práticas pedagógicas, festas cívicas e comemorações no território da cidade e no interior das escolas, operando, de forma competente e densa, com a categoria de cultura escolar. Categoria que é redefinida e ampliada, no sentido de sua problematização, para incluir a construção indissociável entre o rural e o urbano, e suas contraposições, e entre a escola urbana e a escola rural. A autora demonstra que os projetos e campanhas pela promoção da instrução pública e da rede de escolas em nível local, articulavam-se, claramente, aos projetos educacionais então desenvolvidos nas esferas estaduais e nacionais, na chamada Era Vargas (1930-1945). Nesse período, várias reformas foram realizadas nos Estados brasileiros, apropriando-se, inclusive de concepções, modelos e práticas dos chamados escolanovismos e das reformas educacionais ocorridas na década de 1920, assim como do projeto educacional ruralista, entre as quais o incentivo ao contato dos alunos com a natureza, a observação e a obtenção de hábitos de trabalho cooperativo nas escolas. Nesse ideário, o ensino rural não era reconhecido apenas por sua especificidade devido às necessidades de sua localização geográfica, mas, sobretudo, como meio de incorporar as diferenças locais e regionais para formar a nação e a nacionalidade. Para além dos anos de 1930, a interiorização da escola pelo país, o nacionalismo, o higienismo e a eugenia, como perspectivas teóricas presentes entre intelectuais e educadores, ainda ocuparam grande parte dos discursos e da agenda educacional, prosseguindo as disputas em torno dos sentidos da escolarização nas cidades e no meio rural.

A partir de pesquisa minuciosa e densa em variadas fontes documentais e farta bibliografia especializada, interpretada por meio de rico e fértil referencial teórico-metodológico, a autora nos convence da pertinência e da originalidade da sua tese e das hipóteses, que constituíram o eixo de sua operação historiográfica. Assim, demonstra que a construção de Nova Iguaçu e os processos de escolarização, entre os anos de 1916 
a 1950, integraram um mesmo processo (heterogêneo e dinâmico) de ordenação do social, das funções rurais e urbanas, em face da reconfiguração das relações capitalistas no campo e na cidade. Processo este profundamente marcado pela manutenção das formas de dominação e de hegemonia dirigidas pelos grupos econômicos e políticos locais e regionais, em especial os representantes da citricultura no Estado do Rio de Janeiro. "Entre laranjas e letras», a escola, no distrito-sede de Nova Iguaçu, foi estabelecida na confluência, e em meio às tensões entre os projetos de progresso e modernização rural e urbana, e as contradições impostas pela manutenção da precariedade e da pobreza, a estrutura desigual e hierárquica da sociedade e das contradições que assolavam a vida da população trabalhadora.

Fugindo dos marcos canônicos de uma historiografia que enrijeceu as fronteiras entre escolarização urbana e escolarização rural, a autora defendeu a tese de que a educação integrou o processo de capitalização do campo, associando a industrialização à produção agrícola e rural. O letramento, via escola, aparecia vinculado ao ideário em prol do higienismo, da promoção da educação cívica, do desenvolvimento de uma disciplina do tempo e do espaço e da formação do povo. Tratava-se de educar o trabalhador do campo e da cidade, preparando a força de trabalho a uma nova cultura, aos novos ritmos, aos processos e técnicas industriais exigidas para a ocupação de um lugar no mercado internacional para a citricultura. Tratava-se de associar a escolarização ao projeto de modernização conservadora, impondo a estrutura urbana como modelo e local de assentamento do poder político e administrativo em Nova Iguaçu.

Tal projeto de escolarização, encampado por intelectuais, agentes públicos, professores e professoras, comerciantes, agricultores, grupos locais e moradores, evidentemente, esbarrou nos próprios limites históricos, nas condições materiais desiguais e nas disputas políticas (nacionais, regionais e locais), e de classe, inerentes ao processo de desenvolvimento do capitalismo no país. Limites e disputas observadas, minuciosamente, por Amália Dias, na interpretação e no cruzamento de fontes, na observação da heterogeneidade e da diversidade na distribuição, localização e condição das escolas e das populações que eram atendidas pela rede pública e particular, municipal e estadual, em Nova Iguaçu. A despeito das intenções e dos projetos políticos que engrandeciam a escola como 
construtora da modernidade, as escolas padeciam de recursos, professores e professoras trabalhavam em meio ás dificuldades, à exploração do trabalho e aos baixos salários nas áreas urbanas e rurais. Crianças negras, muitas vezes admitidas nas escolas particulares, como evidência de projetos familiares que creditavam à escolarização a representação de meio fundamental de socialização e de educação de sua prole, encontravam dificuldades de acesso e permanência nas escolas públicas. As tenções, as disputas, as contradições, a expansão e os limites do processo de escolarização no município de Nova Iguaçu foram analisados por Amália Dias, ao inquirir relatórios, mapas, dados estatísticos, fotografias, falas e relatos de professores e professoras, moradores, políticos e intelectuais locais, nas folhas da imprensa e também nas diversas fontes documentais consultadas.

O livro de Amália Dias, Entre laranjas e letras: processos de escolarização no distrito-sede de Nova Iguaçu (1916-1950), tornou-se, hoje, obra de referência obrigatória para os pesquisadores e estudiosos da educação brasileira. É ainda mais importante em face das permanências estruturais, das desigualdades e contradições persistentes na atualidade quanto ao acesso à educação escolar, sobretudo nas áreas interioranas e rurais do país. Essa desigualdade também é manifesta na produção historiográfica sobre a educação que, sem dúvida, continua a investir, majoritariamente, na reconstrução da cultura escolar urbana. No âmbito da pesquisa em história da educação, a professora Amália Dias apresenta contribuição extremamente significativa para um problema ainda pouco explorado pela historiografia em suas múltiplas dimensões: a compreensão de que a educação escolar pública, no campo e, não apenas na cidade, emergiu como símbolo e marco da modernidade e do progresso republicanos, articulados aos projetos políticos locais, regionais e nacionais.

Alessandra Frota Martinez de Schueler Universidade Federal Fluminense (Rio de Janeiro, Brasil) alefrotaschueler@gmail.com 